\title{
Rectus Sheath Hematoma
}

\author{
Satoshi Kurisu, Ichiro Inoue and Takuji Kawagoe
}

Key words: computed tomography, abdominal pain

(Inter Med 48: 81, 2009)

(DOI: 10.2169/internalmedicine.48.1476)

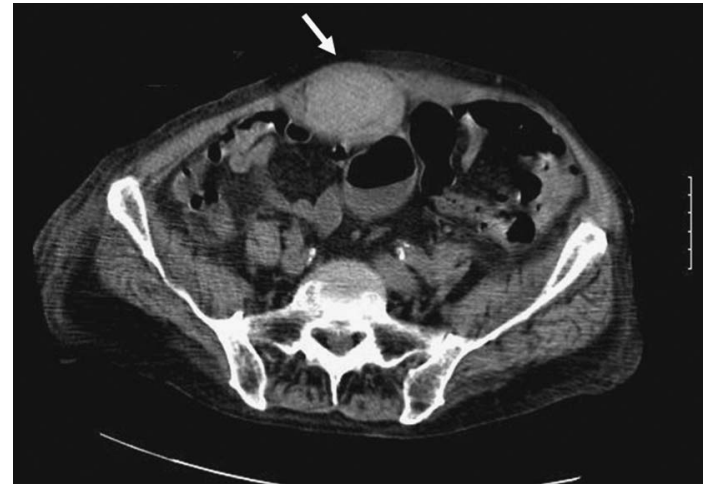

Picture 1. Computed tomography showed a round and high density mass $(70 \times 45 \mathrm{~mm})$ (arrow) in the rectus sheath. No intra-abdominal pathologic findings were identified.

An 81-year-old man taking warfarin for aortic valve re- placement and atrial fibrillation complained of sudden abdominal pain. Physical examination revealed a tender mass, and computed tomography showed a round and high density mass $(70 \times 45 \mathrm{~mm})$ in the rectus sheath (Picture 1 , arrow). No intra-abdominal pathologic findings were identified. The hemoglobin level was decreased from $9.1 \mathrm{~g} / \mathrm{dL}$ to $7.7 \mathrm{~g} / \mathrm{dL}$, and the prothrombin time was 39.7 seconds (international normalized ratio, 3.47). The creatine kinase was increased at 1,537 IU/L. He was diagnosed with rectus sheath hematoma, and anticoagulant treatment was discontinued. His symptom disappeared the following day, and rectus sheath hematoma was spontaneously resolved.

Clinicians should recognize that rectus sheath hematoma is one of etiologies of sudden abdominal pain, especially in patients receiving anticoagulant treatment (1). Magnetic resonance imaging is another useful method in the diagnosis of rectus sheath hematoma (2).

\section{References}

1. Donard PJ, Fetter JC, Zacharski JR. Rectus sheath hematoma complicating low-molecular weight heparin therapy. Int J Lab Hematol 29: 190-194, 2007.
2. Fukuda T, Sakamoto I, Kohzaki S, et al. Spontaneous rectus sheath hematomas: clinical and radiological features. Abdom Imaging 21: 58-61, 1996.

Department of Cardiology, Hiroshima City Hospital, Hiroshima

Received for publication July 5, 2008; Accepted for publication September 6, 2008

Correspondence to Dr. Satoshi Kurisu, skurisu@nifty.com

(C) 2009 The Japanese Society of Internal Medicine Journal Website: http://www.naika.or.jp/imindex.html 